\title{
A Psychometric Study of Political Engagement in the Kyrgyz Republic: An Analysis of Electoral Participation
}

\begin{abstract}
Altynbek Ismailov, Makhinur Mamatova
American University of Central Asia, Bishkek, Kyrgyz Republic

Linkages between personality traits and voter turnout $(\mathrm{N}=555)$ in Kyrgyz Republic were assessed using on an online survey testing for the Five Factor Model (FFM) of personality, crossed checked against the Central Elections Committee of the Kyrgyz Republic's voter participation database. Contrary to the existing literature, our findings suggest that there is no universal personality trait that is responsible for election participation. We find that electoral contexts determine the personality types interested in participating in each election. This has important implications for the development of voter mobilization strategies. Such campaigns should consider particular electoral circumstances and target potential voters who are discouraged to vote.
\end{abstract}

Keywords: elections, go-to-vote, elections mobilization, personality traits, youth

\section{Introduction}

Studies in political psychology in Central Asia are extremely thin. Despite the fact that the socio-political life in Kyrgyzstan and the region is distinguished by a pronounced dynamism and complexity of political processes, attention to the psychological aspects of political behavior and its various forms is still insufficient. Kyrgyzstan is a post-Soviet republic in Central Asia where democratic institutions are just being formed. Citizens' political engagement is often encouraged through perverse incentives such as paying for votes, promising political positions, and instigating identity conflicts. Such incentives may negatively affect democratic formation, creating class of citizens who have mercantilist attitude towards governing bodies. Young citizens, aged from 18 to 29, are interesting because they account for one third of voting population, and, yet, only $43 \%$ participated in the 2017 Presidential Elections as compared to the overall voter turnout of 55\% (State Registration Service, 2019).

This research focuses on identifying personality traits of young citizens that can predict future political participation, such as turning out in elections. The question we addressed was whether personality traits could be used to build highly customized and personally framed mobilization messages that would spark youth

This research was conducted with the support of funding from the United States Agency for International Development (USAID) "Building the Future" Grant. The purpose of this grant is to develop the scope of scholarship and research conducted at the American University of Central Asia in accordance with USAID's mandate to enable resilient, democratic societies to realize their full potential. The authors would like to thank USAID and the people of the United States for their help and generosity. Authors thank Aiganysh Aidarbekova for the research assistance with the data management and processing.

Altynbek Ismailov, MPA, Researcher, Department of Economics, American University of Central Asia, Bishkek, Kyrgyz Republic.

Makhinur Mamatova, Ph.D., Psychologist, Associate Professor, Master of Arts Program in Teaching, American University of Central Asia, Bishkek, Kyrgyz Republic. 
interest in politics.

In recent years, the trait-based Five Factor Model (FFM) of personality (Costa \& McCrae, 1992), also known as the Big Five, has received considerable attention in the field of political psychology (Lyons, 1997; Smith, 1997; Schimmack, Oishi, Diener, \& Suh, 2000; Schoen \& Schuman, 2007; Turska-Kawa, 2013; Samek, 2017). The Five Factor model considers personality through the prism of five sustainable trait factors: Openness, Conscientiousness, Extraversion, Agreeableness, and Neuroticism. These trait factors are identified as being present from low to high degrees on a continuum. Overall, the model has been found to effectively explain individual differences and sustainable behavioral patterns associated with broad and general dispositions (Costa \& McCrae, 1992; McCrae \& John, 1992; Buss, 1996).

In testing whether the Five Factor Model of personality can be used to accurately predict citizens' political participation in the form of voter turnout, we expect that alignment with each personality type will have a consistent effect on election participation as predicted by the current literature (Gerber, Huber, Doherty, Dowling, Raso, \& Ha, 2011) which indicates that those who are extroverted and who have high emotional stability are more willing to participate in elections.

The 2015 and 2017 elections in Kyrgyzstan are interesting, not only because of the availability of voting records, but also because both elections used a biometric voter registration system that eliminated possibility of voter fraud related to double voting, false voter identification, and other issues that had been identified in previous elections. Both elections were very important in the context of political stability, but were held under different political contexts. Parliamentary Elections in Kyrgyzstan were held on October 4th, 2015. This was the second election for parliament after the forcible change of political power in April 2010. Fourteen political parties took part in the election. Six of them overcame the 7\% barrier necessary to secure seats in parliament (Organization for Security and Co-operation in Europe, 2016). The highest number of seats was allocated to the ex-president's Social Democratic Party of the Kyrgyz Republic (SDPK). Elections took place in a contentious political environment, with various different parties representative of the political diversity in the country. An automated voting system was introduced for the first time. It helped to minimize violations during voting. Overall, the political environment was democratic, and elections were supposed to bring predictability and stability. However, the introduction of an automated voting system did not guarantee the abuse of administrative resource.

The most recent Presidential Elections in Kyrgyzstan were held on October 15th, 2017 (Organization for Security and Co-operation in Europe, 2018). Perhaps, this was the first truly competitive election in the history of Kyrgyzstan between a presidential candidate supported by the outgoing administration and candidate from the opposition. The ex-president of Kyrgyzstan Almazbek Atambaev strongly supported the election of his party successor, Sooronbay Jeenbekov, who then won the election with $54.2 \%$ of the vote. According to campaign messages, Jeenbekov would ensure stability by continuing the policies that were set by the ex-president. The opposition leader and the main competitor, Omurbek Babanov, were forced to leave the country after the elections.

Since then the political climate in the country has changed significantly. The alignment of political forces has changed, the struggle for power has taken new turns, the territorial conflicts in the south of Kyrgyzstan aggravated, and the opposition is mobilizing forces. Supported by his clan the new president Sooronbay Jeenbekov came into conflict with the ex-president Atambaev who was then arrested and imprisoned. Social tension is growing in the regions. The new political crisis promises to turn into a wave of protests. 


\section{Method}

We ran an online FFM personality test and then identified whether respondents had voted in the previous 2015 and 2017 elections using the official Central Elections Committee voting records. We also asked respondents to crosscheck this for themselves using the official voting database.

We used an online version of the Big Five inventory developed and adapted by Gretsov and Azbel (2012). This instrument measures the five basic tendencies in human personality: Openness, Conscientiousness, Extraversion, Agreeableness, and Neuroticism. The inventory consists of 40 statements measured on a three-point scale and provides scores for each of the five personality factors. The inventory and interpretation of the results are conceptually based on the Five Factor Model of personality by Costa and McCrae (1992).

In order to compare FFM traits with voting behavior, it was necessary to find a reliable way of checking whether the respondent had voted or not. Self-declared voting behavior is not always reliable and tends to overrepresent actual voting turnout (Gerber et al., 2011). To minimize this discrepancy, we used officially published databases from the Central Elections Committee, where names of voters were published for Parliamentary (2015) and Presidential (2017) Elections. After systematizing and sorting names within our own database, we also offered respondents the opportunity to self-report and to check this against their official voting statuses. This allowed us to validate voting statuses and more accurately record voter turnout of individual voters. In addition to collecting information on personality and elections participation, we also collected demographic background information, including age, ethnicity, marital status, employment, and region of residence to control for background characteristics.

A special website was developed to collect the data mentioned above from the respondents. To incentivize respondents to participate in the survey, we offered them the opportunity to learn more about their personality types given their responses as done by the popular Cambridge University the Psychometrics Center (2018). The website allowed for the convenient entering and organization of data. Advertisements about the online research were placed on Facebook and Instagram to inform the respondents about the ongoing survey. Before beginning the survey, respondents were asked to digitally consent to their participation, with the consent form included in the online description of the research.

For the purposes of data analysis OLS regressions using different model specifications was used. Further correlation analysis and t-tests were run to determine any distinguishable differences between groups.

\section{Data}

As discussed above, a special website was used to collect data on Five Factor Model personality traits, elections participation status, and background characteristics. Given that online surveys are associated with issues related to high number of dropouts, repeated entries, unfinished entries, and forms with incorrectly entered data, these were not included in the final data set. Out of 735 records, data from only 555 responses were eligible for analysis. The data were collected between the 1st and 15th of August 2018. We did not trace respondents who dropped out in the middle of the research nor their possible reasons for having done so.

In terms of the geographic distribution of respondents, they were predominantly from Bishkek (76\%), the capital city of Kyrgyzstan. The second greatest source region for responses was Chui Oblast (province), with $8 \%$ of respondents. This result may mirror overall Facebook and Instagram users' demographics. Given the homogeneity, this variable (region) was not used as a control variable as including this variable would result in 
unnecessary decrease in degrees of freedom.

The majority of respondents were Kyrgyz in ethnicity (87\%), and the remaining respondents were Russians (5\%), or other regional nationalities (7\%). Thus, this variable was likewise dropped from the control variable list. Respondents were mostly educated with $65 \%$ having a bachelors or higher education. For the purposes of analysis, this variable was coded from 0 - no education to 8 - doctoral education in to order asses education from low to high.

Gender distribution was skewed more towards female, with only $34 \%$ of respondents being male. In terms of household status, the majority of respondents were either employed or students $(83 \%)$, and $71 \%$ of respondents declared that they were single. For age distribution as was as anticipated based on the method of data collection used, $58 \%$ of respondents were between $18-24$ years old.

Even though respondents were not randomly selected, and responses were self-declared; overall respondents are considered to have fallen within the primary target group for election mobilization campaigns. This group is interesting because it is comprised of individuals between the ages of 19 and 30, the target group for those seeking to reach the youth vote. Furthermore, the group was represented by a high proportion of females - a demographic that was among the least active participants in the 2017 Presidential Elections among this age group.

\section{Results}

In order to properly determine the significance of the role played by each personality profile, the average psychological profile of the respondents with regards to each of the personality traits must be understood. While the study is not necessarily representative of young voters in general and is prone to selection bias, the demographic who participated in the study is an important target group for electoral mobilization. Thus, an understanding of the average profile is a key for future mobilization work.

Participants received higher than average scores for Agreeableness (10.4). A higher than average score was also found for Neuroticism (10.2). Likewise, an above average score for participants was found for Conscientiousness (10.22). In terms of Openness, the majority of respondents scored highly, resulting in an above average (11.3) score of this factor. In terms of Extraversion, respondents received an average score of 7.9. We may describe such a score as a marker of ambiversion tendencies. Ambiversion was found in both female participants (7.9) and males (8.0). In both genders (11.7 in males and 11.1 in females) there was a higher than average score of Openness to new experience. By contrast, Neuroticism was higher on average for females (10.4) than for male respondents (9.51). Agreeableness, however, was above average for both males (10.6) and females (10.3). Statistically significant differences between genders have been found for the factors of Openness $(\mathrm{p}<0.01)$ and Neuroticism $(\mathrm{p}<0.01)$. Male participants reported higher flexibility, curiosity, and receptivity to new experience, and less anxiety in comparison with female respondents. However, in running an additional t-test across gender type and associated factors, statistically significant differences in Gender $(\mathrm{p}<$ $0.01)$, Openness $(p<0.01)$, Neuroticism $(p<0.01)$, and voting in Presidential Elections $(p<0.01)$ variables can be seen.

These findings suggest that controlling for gender in regression specification may be an interesting contribution. In general, we see that men and women shared different background characteristics. In the context of voter mobilization, audience tailored messages may yield higher results.

Thus, our respondents had average or higher than average expression of the five basic dimensions that 
shape the psychological profile of personality. Given that the respondents were mainly young people (mean age $=26.4$ ) who tend to use social media more frequently, this was not unexpected.

There is very weak correlation between voting in elections and any of psychological factors. There is a weak positive correlation $(r=0.38, p<0.01)$ between participating in each of the elections, with voters in the Parliamentary Elections having a higher propensity to vote in the Presidential Elections. The latter phenomenon has been exhaustively described in the existing literature (Green \& Gerber, 2008).

Analysis of the regressions (Table 1) supports existing findings that Age and Education play important roles in election participation, and that Gender is not a significant factor (Gerber et al., 2011).

Table 1

Analysis of Regressions

\begin{tabular}{llll}
\hline & Parliamentary $(\mathrm{N}=504)$ & Presidential $(\mathrm{N}=504)$ & Counted $(\mathrm{N}=504)$ \\
\hline Intercept & -0.216 & $0.381^{*}$ & 0.165 \\
Age & $0.008^{* * *}$ & 0.001 & $0.010^{* *}$ \\
Extraversion & -0.002 & -0.010 & -0.013 \\
Openness & -0.009 & -0.012 & -0.021 \\
Conscientiousness & $0.013^{*}$ & -0.002 & 0.011 \\
Neuroticism & $0.012^{*}$ & 0.004 & 0.016 \\
Agreeableness & 0.003 & $0.014^{*}$ & 0.017 \\
Education & $0.037^{* *}$ & $0.037^{* *}$ & $0.037^{* *}$ \\
Gender & -0.026 & -0.060 & -0.086 \\
Adjusted R-squared & 0.055 & 0.025 & 0.052 \\
\hline
\end{tabular}

Notes. Signif. codes: $0.01>* * *, 0.05>* *, 0.1>*$.

We found that psychological factors have an ambiguous non-uniform effect on voter participation in each election, and that the effects disappear when we consider combined elections.

Contrary to the current literature, we do not find any significant influence of Extraversion on voting participation. We also found that the coefficient for Openness had no significant effect on voting even though this variable is associated with willingness to participate in political processes and community engagement. This is consistent with the literature which indicates that this factor does not explain participation in elections (Vecchione \& Caprara, 2009). Contrary to the findings of Gerber et al. (2011), Conscientiousness was shown to have a somewhat ambiguous effect. No effect is seen for either the presidential or combined regressions; however we see a positive effect in Parliamentary Elections. The positive coefficient of this factor is explained by Gerber et al. (2011) as demonstration of compliance of Conscientious people with social norms, while the negative coefficient was associated with the voter expecting instrumental gains from participation in elections, i.e., more practical benefits. Conscientiousness was negatively associated in Gerber's paper, which may explain the more pragmatic approach to elections participation observed. In our findings, by contrast, Conscientiousness is positively associated.

In the context of the 2015 Parliamentary Elections in Kyrgyzstan, it was the first such election completed in a democratic manner during peacetime, and it was considered an important civic duty to participate. This would make it more attractive to voters who are more willing or eager to comply with social norms. Neuroticism was also shown to have had a positive effect in Parliamentary Elections, but no effect on the Presidential Election. In the literature, Neuroticism was shown to have a negative association with election 
participation. Gerber et al. (2011) claim that, the other end of the Neuroticism spectrum, Emotional Stability, is positively related to participation in elections. Though there have also been mixed results shown by studies of the impacts of this factor on political participation (Anderson, 2009; Mondak, Canache, Seligson, \& Hibbing, 2011), Gerber et al. (2011) claim that emotionally stable voters are more willing to handle political contention and participate in elections. Our results, on the other hand, run contrary to these. Neuroticism is positively associated with participation in the Parliamentary Election (or in other words Emotional Stability is negatively associated). This finding can be explained by the fact that the election in 2015 was considered to have been important for the political stability of the Kyrgyz Republic, and we would expect that those who score highly on Neuroticism would prefer to increase political stability by participating in such elections.

Similarly, Agreeableness had no discernable effect in the Parliamentary Elections, but was positively associated with participation in the 2017 Presidential Election. In the literature, Agreeableness is negatively associated with turnout because it is anticipated that agreeable people would eschew the political conflict inherent in elections (Gerber et al., 2011). Our results may be explained by the fact that, in the 2017 Presidential Elections, the former President called upon voters to vote for his candidate in order to decrease potential conflict. This, thus, possibly mobilized agreeable voters.

\section{Discussion}

The findings of this research emphasize three important points. First, electoral context plays a great role. The salience of certain issues in elections may mobilize different types of personalities. For instance, if potential for stability plays an important role in the election, then voters who have a high Neuroticism score could be more willing to vote (as they did in the 2015 Parliamentary Elections); whereas, in situations such as the contentious Presidential Elections of 2017 such voters would eschew electoral participation. The same logic could be applied to other personality factors, and the results do provide evidence to indicate that different factors have different salience in different elections.

Second, given the varying contexts of each election, counting or indexing different elections into one for regression analysis may result in information loss. As we can see in Table 1, the salience of psychological factors disappears in the last column where the two elections were combined into one dataset.

Third, these findings have important implications for voter mobilization campaigns. Instead of developing a one-size-fits all mobilization strategy for different elections, organizers must take into account electoral context and target voters who are less likely to vote in that context. Testing of this last hypothesis, however, requires further research.

The findings suggest that there may not be universal personality factors that explain electoral participation of voters, especially in developing countries such as Kyrgyzstan. Even though respondents in this study are not representative of the general population, they represent an important stratum of the population that needs to be mobilized for participation in political processes such as elections. Mobilization strategies should take into consideration the context of elections and what types of personalities are likely to vote under the given circumstances. This will provide insights on how to mobilize voters who have lower propensity to vote by compiling tailored messages that would appeal their personalities. The link between different contexts and the mobilization of particular personalities is an under researched topic that needs further investigation. As is the impact of narratives of political figures, attitudes of mass media and political fragility define what type of voters will participate in voting. The research points out that, in emerging democracies, electoral processes are 
not stable and have different salience for each personality type of voters.

\section{Conclusion}

In this study, we investigated whether there is a strong association between five personality trait factors and voter turnout. Contrary to our expectations, our findings suggest that there is no universal set of personality trait factors that consistently affects willingness to vote. More interestingly, we find that, depending on the election context, different sets of personality factors play statistically significant roles in explaining voter mobilization. This suggests that, it is not personality factors per se, but electoral contexts which define what trait types of voters go to vote. For example, if the elections will play an important stabilizing role in the political environment of a country, then those who score highly on Neuroticism have higher propensity to vote. On the other hand, if influential and established political figures call on voters to vote for a particular political candidate, then those who score highly in terms of Agreeableness are more likely to vote. These findings give policymakers important insights into the ways of increasing the effectiveness of voter mobilization campaigns.

\section{References}

Anderson, M. R. (2009). Beyond membership: A sense of community and political behavior. Political Behavior, 31(4), 603-627. doi:10.1007/s11109-009-9089-x

Buss, D. M. (1996). Paternity uncertainty and the complex repertoire of human mating strategies. American Psychologist, 51(2), 161-162. doi:10.1037//0003-066X.51.2.161

Cambridge University the Psychometrics Center. (2018). Retreived from https://discovermyprofile.com/tag/Personality

Costa, P. T., \& McCrae, R. (1992). Normal personality assessment in clinical practice: The NEO personality inventory. Psychological Assessment, 4(1), 5-13. doi:10.1037//1040-3590.4.1.5

Gerber, A. S., Huber, G. A., Doherty, D., Dowling, C. M., Raso, C., \& Ha, S. E. (2011). Personality traits and participation in political processes. The Journal of Politics, 73(3), 692-706. doi:10.1017/S0022381611000399

Green, D. P., \& Gerber, A. S. (2008). Get out the vote: How to increase voter turnout. Scientific American Mind. Retreived from http://www.nature.com/scientificamericanmind/journal/v22/n6/full/scientificamericanmind0112-9b.html\%5Cnhttp://books.g oogle.com/books?hl=en\&lr=\&id=LKGaYyZqZbEC\&oi=fnd\&pg=PR7\&dq=Get + Out + the + Vote. + How + to + increase + Voter + Turnout\&ots $=$ 4ChUIkAGi\&sig=srwbV42ZMr9I

Gretsov, A., \& Azbel, A. (2012). Psychological tests for senior pupils and students. Peter; St. Petersburg. doi:10.1177/0002764207300040

Lyons, M. (1997). Presidential character revisited. Political Psychology, 18(4), 791-811. doi:10.1111/0162-895X.00079

McCrae, R. R., \& John, O. P. (1992). An introduction to the five-factor model and its applications. Journal of Personality, 60(2), 175-215. doi:10.1111/j.1467-6494.1992.tb00970.x

Mondak, J. J., Canache, D., Seligson, M. A., \& Hibbing, M. V. (2011). The participatory personality: Evidence from Latin America. British Journal of Political Science, 41(1), 211-221. doi:10.1017/S000712341000027X

Organization for Security and Co-operation in Europe. (2016). Kyrgyz Republic, Parliamentary Elections, 4 October 2015: Final report. Retrieved from https://www.osce.org/odihr/elections/kyrgyzstan/219186

Organization for Security and Co-operation in Europe. (2018). Kyrgyzstan, Presidential Election, 15 October 2017: Final report. Retrieved from https://www.osce.org/odihr/elections/kyrgyzstan/374740

Samek, A. (2017). The association between personality traits and voting in the 2016 U.S. Presidential Election. Paper No. 2017-002 Cesr-Schaeffer.

Schimmack, U., Oishi, S., Diener, E., \& Suh, E. M. (2000). Facets of affective experiences: A framework for investigations of trait affect. Personality and Social Psychology Bulletin, 26(6), 655-668. doi:10.1177/0146167200268002

Schoen, H., \& Schumann, S. (2007). Personality traits, partisan attitudes, and voting behavior. Evidence from Germany. Political Psychology, 28(4), 471-498. doi:10.1111/j.1467-9221.2007.00582.x

Smith, M. B. (1997). The authoritarian personality: A re-review 46 years later. Political Psychology, 18(1), 159-163. doi:10.1111/0162-895X.0005

State Registration Service. (2019). Election analytic. Retrieved from https://data.srs.kg/statistics/region.xhtml 
Turska-Kawa, A. (2013). Big five personality traits model in electoral behaviour studies. Romanian Journal of Political Science, 13(2), 69-105.

Vecchione, M., \& Caprara, G. V. (2009). Personality determinants of political participation: The contribution of traits and self-efficacy beliefs. Personality and Individual Differences, 46(4), 487-492. doi:10.1016/j.paid.2008.11.021 